\title{
Defining the concept of fair pricing for medicines
}

\section{Suerie Moon and colleagues consider what makes a fair price for both buyers and sellers}

T工 igh and rising prices of medicines have attracted public concern from the poorest to richest countries. For example, of 1500 patient groups surveyed in 78 countries, only $9 \%$ believed that pharmaceutical companies were "excellent or good" at having "fair pricing policies". This figure has hovered between $11 \%$ and $15 \%$ since the survey began in 2011. ${ }^{1}$ Politicians, experts, physicians, patients, and pharmaceutical executives have hotly debated whether medicines prices are fair, but without agreeing on what "fairness" means.

Medical, public health, and economic texts do not provide a standard definition of a fair price for medicines. Discussions of fair pricing of goods generally, however, provide some useful indications. These include the characteristics intrinsic to the product, market, and transaction at a point in time, and the perceptions of consumers and suppliers. ${ }^{2-6}$ European competition law defines whether a price is excessive based on several factors, including production

\section{KEY MESSAGES}

- Several key factors can reasonably shape views of fairness in medicines prices, considering the perspectives of both sellers and buyers

- For sellers, a reasonable price floor could include costs of R\&D, manufacturing, and distribution; other related costs (eg, registration, administration, pharmacovigilance); and a fair profit

- For buyers, a reasonable price ceiling could include considerations of present and future affordability, value to the individual and health system, and security of supply

- A fair price is any price between the price floor and ceiling

- Pricing under the floor threatens sustainable supply and future innovation whereas pricing above the ceiling unduly limits benefits for the individual and health system

- Pricing outside the the fair pricing zone merits public action costs, profit margins, economic value, and prices of related goods. ${ }^{7}$

Drugs, biological agents, diagnostics, and other medical devices-which for brevity we call medicines-are not ordinary goods. The price of a medicine should allow for meeting the societal need for that product. Sellers often have strong price setting power, however, when need is greatest. For new medicines, monopoly power strengthens a seller's position. These characteristics mean that government intervention is often needed to ensure a fair price.

Here we describe a conceptual framework for assessing whether a medicine's price is fair. The framework was initially developed for the 2016 meeting of the WHO Advisory Group on Fair Pricing and revised after expert feedback and discussion. Increased clarity about a fair price, we argue, can help to achieve it.

\section{Defining sellers and buyers}

We divide those likely to have different views of fair pricing into "sellers" and "buyers."

Sellers include several subgroups. One subgroup is developers conducting research and development (R\&D). These comprise academic and government laboratories for basic research, small companies developing a promising technology in preclinical and clinical trials, larger companies developing medicines through regulatory approval, and generic firms adapting formulations. A second subgroup is manufacturers, who may or may not be distinct from developers. A third subgroup includes distributors moving medicines from manufacturers towards patients and the public-for example, wholesalers, importers, pharmacies, healthcare facilities, online retailers, and informal outlets.

Buyers include those who pay for a medicine, such as households, insurers, ministries of health, and donors. We also include those who benefit from a medicine, such as patients for therapeutics, or entire populations for prophylactics (eg, vaccines, drugs). The public is ultimately the buyer of medicines, whether through out-of-pocket payments, private insurance premiums, or taxes for publicly financed health insurance. Public perceptions of fairness matter.

\section{Fairness to sellers}

For sellers, we identified four categories to be considered when assessing fairness.

First is the cost of R\&D through to regulatory approval. There is no single, widely agreed method to calculate such costs. Several approaches could be considered, including the cost of successfully developing a specific medicine or a company's total costs including failures. Failures across the industry as a whole need not be included, but they should be reflected in the risk premium in a company's cost of capital. Direct public funding of R\&D and tax benefits should be subtracted from total costs. The opportunity cost of capital and excessive executive salaries could be excluded entirely. ${ }^{8}$ A major challenge is the paucity of public data on R\&D costs. ${ }^{9}$ Increasing cost transparency is likely to require government action. This has been proposed in many public forums ${ }^{10-12}$ and expert reports. ${ }^{1314}$

The second category is the cost of manufacturing and distribution. Data on manufacturing costs are not usually made public. Costs may be discovered, however, by prices under competitive market conditions or estimated by experts using prices of inputs. ${ }^{15} 16$ Medicines have considerable economies of scale, and predictability of orders and payment enables suppliers to manufacture efficiently. Therefore, a lower price may be considered fair for large volume orders placed in advance with secured payment, compared with a higher price for smaller volumes or rush orders. The costs of distribution may also contribute appreciably to prices.

The third category is fair profit. For commercial sellers, generating a fair return on investment is their main purpose. Pharmaceuticals and biotechnology are consistently ranked among the most profitable industries by various measures. ${ }^{17}$ Profit margins vary widely across sellers, however, and no clear norms have emerged on what is fair. Several approaches to assessing fairness are possible. These include comparing 
average profit margins and cost of capital across different industries, ${ }^{17}$ or specific targets (eg, GlaxoSmithKline has aimed for a $14 \%$ return on $R \& D$ investment ${ }^{18}$ ). In principle, allowable profit margins can take into account the risk inherent in R\&D, providing both reward for past success and capital for future innovation, without permitting excessive profits. In practice, further data and analysis are required to assess, and develop guideposts for gauging, the overall fairness of profits.

Finally, other normal costs of doing business should be considered. These include registration in different countries after initial regulatory approval, administration, and postapproval surveillance for adverse effects (eg, pharmacovigilance systems, phase IV trials). Consensus on whether a fair price should include marketing costs is unlikely, however, given robust debates on the extent to which suppliers should market medicines to healthcare providers or directly to consumers.

\section{Fairness to buyers}

For buyers, we identified three categories of demand-side factors. The first is affordability, which is the ability to purchase a "necessary quantity" of a medicine without undue financial hardship. ${ }^{19}$

Determining the necessary quantity depends on a number of factors, which are different for individuals and populations. For example, for individuals, necessity is determined by the properties of the medicine and underlying disease, such as efficacy, availability of alternatives, and severity of the consequences of non-provision. At the population level, necessity may be determined by factors such as the infectiousness of a disease, equity concerns, or degree to which a government is legally obliged to provide a medicine. When the necessary quantity of a medicine is high, achieving affordability would probably require a lower price for it to be considered fair.

Financial hardship is determined by financial burden and resources available to a buyer. Resources need to be assessed in relation to a specific buyer. For example, a price that is affordable to an insurer, which spreads costs across a population, may not be affordable for an individual paying out of pocket. Similarly, a price that is affordable to an international donor may not be affordable to the government of a country where the disease is endemic. Perceptions of affordability will also vary according to income, psychological, or cultural factors.
These considerations underline the importance of assessing fairness of prices specific to a buyer rather than in isolation.

Several methods are available for determining hardship. Approaches have been developed based on individual or household income, insurance coverage, and other available resources. ${ }^{14}$ Four possible tests are: the line for catastrophic health expenditure, drawn at a maximum of $40 \%$ of a household's income after subsistence needs are met or $25 \%$ of total household expenditure, ${ }^{2021}$ impoverishing expenditure that pushes a household below a poverty line of $\$ 1.25$ (£1; €1.11) or $\$ 2$ per capita/day, ${ }^{21}$ or expenses above $7.5 \%$ of adjusted gross income (US tax standards). ${ }^{22}$ Empirical evidence, such as survey data on the degree to which prices impede patient adherence to prescribed medicines ${ }^{23}$ could also indicate hardship. Since patients often need more than one drug for chronic conditions, total financial burden will shape affordability of any given medicine.

For governments, financial hardship depends on need, available budget, and the ability to sustainably increase a budget. ${ }^{24} \mathrm{~A}$ key challenge is that government spending on health, and medicines, in particular, varies widely by country. ${ }^{25}$ Several targets have been proposed to provide guidance for a fair level of collective health spending: a minimum of $5 \%$ of $\mathrm{GDP}^{26}$ or $15 \%$ of government budgets on health, ${ }^{27}$ a maximum of $1 \%$ of government health expenditure on vaccines, ${ }^{28}$ or a threshold for each quality adjusted life year provided by a medicine.

A second factor for buyers in assessing fairness is value to the individual and the health system. Buyers increasingly use health technology assessment to assess a medicine's benefits in relation to price. However, such assessment requires strong evidence and robust monitoring capacity, raising challenges for its widespread use. Furthermore, sellers have increasingly adopted value based pricing. This has various definitions ${ }^{29-31}$ but generally refers to linking price to valued characteristics of a medicine (eg, therapeutic efficacy, health system efficiencies). ${ }^{32}$ In principle, paying higher prices for better medicines should provide incentives for development of better products. In practice, value based pricing can far exceed affordability thresholds. ${ }^{33}$ This occurred, for example, when hepatitis $\mathrm{C}$ drugs were priced at the same level as liver transplantation, and led to rationing. ${ }^{34}$ A key question is whether pricing can reflect value while remaining affordable.
A third factor is supply security. Buyers need adequate, timely supply, which may justify paying higher than minimum prices. Paying above the lowest price is merited to retain multiple suppliers in a market as this can reduce the risk of shortages and encourage competition. For example, Unicef procures vaccines from several suppliers for these reasons. ${ }^{35}$ Similarly, some governments have paid higher prices to support local production of medicines for the sake of supply security. ${ }^{36}$

\section{Fair pricing zone}

We combined the above factors into a framework in which a fair pricing zone lies between a price floor and ceiling. The price floor is the lowest sustainable price at which suppliers can sell a medicine. It can include the cost of R\&D, manufacturing, and distribution, other costs, and a fair profit. The price floor should incentivise innovation and maintain competition. The price ceiling is the maximum the buyer can afford. Prices above the ceiling are defined as excessive and would justify regulation.

Figure 1 shows the framework for a simplified hypothetical scenario in which one seller produces three bottles of a drug and sells one to each of three buyers: a high, medium, and low resource buyer (analogous to different countries, organisations, or individuals). We assign values to each of the cost components, such that it costs the seller $\$ 30$ to offer the drugs for sale, including a fair profit margin; R\&D costs are allocated equally to the three buyers. The size of each cost component

$$
\begin{aligned}
& \text { (Minimum sustainable) profit margin } \\
& \text { Distribution costs } \\
& \text { R\&D costs } \\
& \text { Average cost of production } \\
& \text { Marginal cost of production } \\
& \text { - Price ceiling (maximum affordable price) }
\end{aligned}
$$

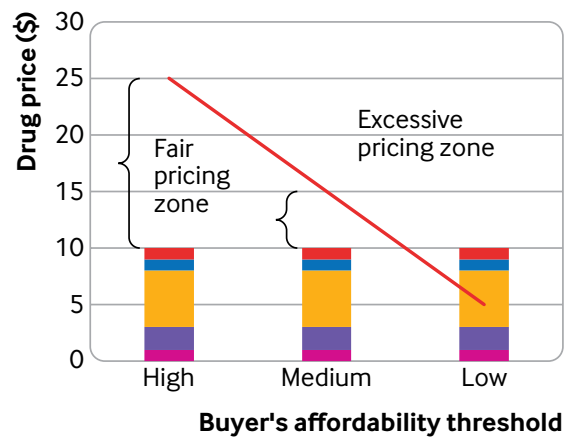

Fig 1 | Hypothetical price ceilings (ie, the maximum that is affordable to the buyer) and fair prices for countries with different affordability thresholds 
will vary widely; this illustration merely identifies the components to be considered. We assign a maximum affordable price (ceiling) of \$25/unit for the high resource buyer, \$15/unit for the medium resource buyer, and \$5/unit for the low resource buyer. In this scenario, all costs are distributed equally across the three buyers.

In fig 1 , any price falling between the affordability line (price ceiling) and the cost column (price floor, set here at \$10)) would be considered "fair." The exact price within the fair pricing zone would determine the distribution of producer or consumer surplus, but all prices would be fair. Consumer (or buyer) surplus is the benefit that accrues to consumers when a product is priced below their maximum willingness to pay. Conversely, surplus accrues to the producer when the price lies above the lowest the producer is willing to charge. Considerations of who receives the surplus highlight the distributional implications of medicines pricing but are often absent in pricing discussions.

If a medicine offers greater value, the high and medium resource buyers could agree to a higher price that is still within an affordable range. Notably, the high resource buyer could pay a price that is lower than the medium resource buyer. As long as both prices fall below each buyer's affordability thresholds, the prices would be considered fair-that is, fairness does not require wealthier buyers to pay higher prices than less wealthy ones, as long as prices are affordable to both. For the low resource buyer, however, the price floor exceeds
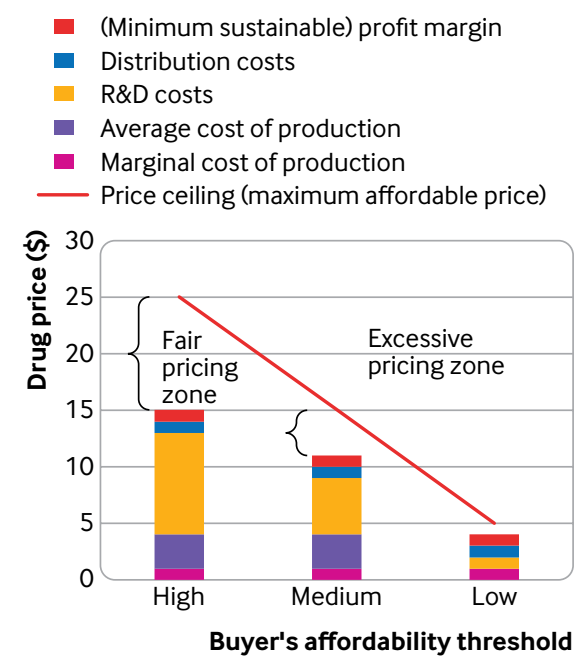

Fig 2 | Price ceilings and fair prices for countries with different affordability thresholds when research and development costs are distributed progressively the ceiling-that is, even the lowest price of $\$ 10$ is not affordable. A subsidy from government, donors, or other third parties can bridge the gap between the $\$ 10$ lowest price and the $\$ 5$ the buyer can afford.

In a second scenario (fig 2 ), $R \& D$ costs are distributed progressively-for example, countries could pay a proportion of global R\&D costs based on their share of the global economy. The low resource buyer pays the marginal rather than the average cost of production. The total cost to the seller (\$30) remains the same, but the zone of fair pricing becomes narrower for the high and medium buyer. The low buyer can now afford the product within a fair pricing zone of between $\$ 4$ and $\$ 5$.

In these scenarios, fair prices are those that fall under the affordability line and excessive prices are those above it. This requires sellers being able to sell an adequate quantity in high and medium resource markets to cover their R\&D and average production costs. This is feasible for medicines needed worldwide but more challenging for those predominantly used in poorer countries, such as those for sleeping sickness.

In a third scenario, R\&D financing is delinked from the price of the end product (and removed from the cost columns) (fig 3). The price floor drops for all three buyers, though other costs could still be progressively spread across the three. However, the R\&D costs still need to be covered by, and distributed among, buyers in some other form. ${ }^{37}$

\section{Applying the concept of fair pricing}

In summary, a fair price for a medicine is affordable to the buyer while covering the seller's costs and providing a reasonable profit margin. Within a fair pricing zone, a specific price may be higher or lower, possibly reflecting value or distribution of consumer and producer surplus.

We simplified the framework and hypothetical scenarios to emphasise key concepts. Applying the framework to decision making would require access to data on $R \& D$, manufacturing, and distribution costs, which is generally not publicly disclosed. This lack of transparency about costs undermines efforts to assess the fairness of medicines prices, ${ }^{1038}{ }^{39} \mathrm{It}$ also exacerbates information asymmetry to the sellers' advantage. Nevertheless, disclosure can be enforced through legislation, regulation, and judicial action or as a condition of receiving public research funds, tax benefits, regulatory approval, or listing in a formulary for reimbursement. In
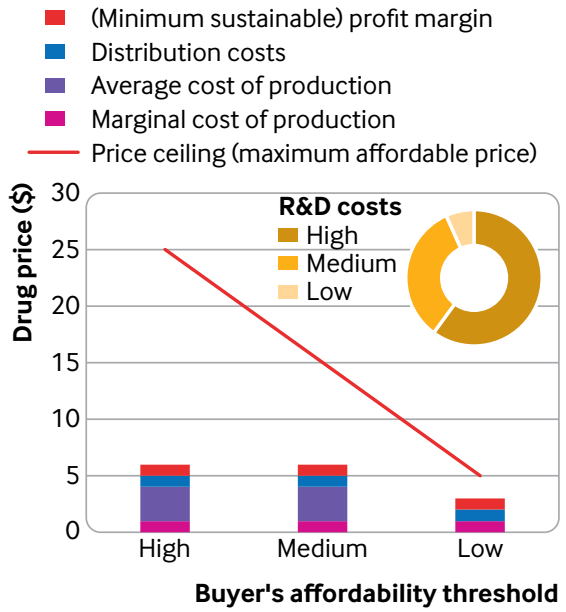

Fig 3 | Price ceilings and fair prices for countries with different affordability thresholds when research and development costs are delinked from the price of the end product

the absence of disclosure, decision makers may rely on reasonable estimates based on publicly available information.

The framework would require further analysis of key topics, including identifying affordability thresholds for particular buyers, assessing the fairness of profit margins, allocating global R\&D costs across countries or buyers, and incorporating value assessments into the price. The framework's application would vary by country (or subnational body, such as an insurer). Some countries will have greater negotiating leverage, ability to mandate information disclosure, access to health technology assessment expertise, and a wider zone of fair pricing than others. The analytical questions are challenging but not insurmountable.

This framework does not fix a fair price for a medicine through a cost plus formula. Rather, it provides a way of systematically assessing whether any given price is fair by taking costs into account. The framework argues for a concept of pricing that explicitly takes into account the needs of both sellers (whether originator or generic) and buyers, and the broader public interest objectives of securing innovation, sustainable supply, and affordability. In so doing, it seeks to deal with several contentious problems and help advance the public debate on medicines pricing. The framework also accounts for the globalised nature of markets for medicines, and the need to consider fairness across widely differing situations and buyers. In addition, it allows for adjustment of prices to reflect the value of a medicine within 


\begin{tabular}{ll}
\hline $\begin{array}{l}\text { Table } 1 \text { | Information and analysis needed to apply this fair pricing framework } \\
\text { Factors to consider }\end{array}$ & Information and analysis needed \\
Sellers & Usually not disclosed, feasible but contentious to estimate \\
\hline Cost of R\&D & $\begin{array}{l}\text { Usually not disclosed, feasible to estimate, disclosed in } \\
\text { competitive markets }\end{array}$ \\
\hline Cost of manufacturing and distribution & $\begin{array}{l}\text { Aggregate profit disclosed but not product-specific; benchmarking } \\
\text { feasible; entails normative judgment }\end{array}$ \\
\hline Fair profit & Usually not disclosed, feasible to estimate \\
\hline $\begin{array}{l}\text { Other costs (registration, } \\
\text { administration, pharmacovigilance) }\end{array}$ & $\begin{array}{l}\text { Further analytical work needed to identify concrete affordability } \\
\text { ceilings for specific buyers }\end{array}$ \\
\hline Buyers & $\begin{array}{l}\text { Health technology assessment can contribute; methods needed to } \\
\text { incorporate value within pricing under affordability constraint }\end{array}$ \\
\hline Affordability & $\begin{array}{l}\text { Information on volumes and producers needed to maintain } \\
\text { competition and supply for specific product, feasible to collect }\end{array}$ \\
\hline Value to the individual and health system
\end{tabular}

the constraint of affordability. Finally, it highlights the types of missing data needed to make solid determinations of whether a price is insufficient, fair, or excessive (table 1).

A clear concept of fairness in medicines pricing, combined with further analysis and access to information, would strengthen society's ability to assess and achieve fair prices for all.

We thank Inthira Yamabhai and Gary Humphreys for valuable comments received on an earlier version of this paper; Elise Erickson for assistance in preparing the manuscript; and members of the WHO informal advisory group on fair pricing and participants at the Fair Pricing Forums in Amsterdam, the Netherlands (May 2017) and Johannesburg, South Africa (April 2019) for valuable discussions that informed this article.

Contributors and sources: SMo has conducted research for over two decades on policies to achieve more globally equitable innovation and access to medicines. She is a member of the expert advisory group for the WHO Fair Pricing Forum and leads research at the Global Health Centre of the Graduate Institute of Geneva. SMa is an expert in vaccine pricing and procurement. She has worked for the private sector, non-governmental organisations, and WHO. She has contributed to improving vaccine price globally, particularly aiming at facilitating access to vaccines in middle income countries. IK is Japan's foremost expert in health technology assessment, serving as a project professor of health technology assessment at the University of Tokyo, Japan, since 2012, as a research director at the Canon Institute for Global Studies, Tokyo, and as an advisory expert for WHO and OECD. HBP is a health systems expert in pharmaceutical sector development. She has worked for WHO and Unicef for more than two decades in Europe, Asia and Africa. All authors meet ICMJE criteria for authorship.

Competing interests: We have read and understood BMJ policy on declaration of interests. No specific funding was received for the development of this manuscript. SMo, SMa, and HBK have no relevant interests to declare. IK has received grants from Crecon Medical Assessment, Ono Pharmaceutical, Dickinson and Company Japan, and Takeda Pharmaceuticals outside the submitted work.

Provenance and peer review: Commissioned; externally peer reviewed.
This article is part of a series proposed by the $\mathrm{WHO}$ and commissioned by The BMJ.The BM/ retained full editorial control over external peer review, editing, and publication of these articles. Open access fees are funded by WHO.

Suerie Moon, director of research ${ }^{1,2}$

Stephanie Mariat, technical officer ${ }^{3}$

Isao Kamae, professor ${ }^{4}$

Hanne Bak Pedersen, programme manager ${ }^{5}$

${ }^{1}$ Global Health Centre, Graduate Institute of International and Development Studies, Geneva, Switzerland ${ }^{2}$ Harvard TH Chan School of Public Health, Boston, USA ${ }^{3}$ World Health Organization, Geneva, Switzerland ${ }^{4}$ Graduate School of Public Policy, University of Tokyo, Japan

${ }^{5}$ Health Technologies and Pharmaceuticals, WHO Regional Office for Europe, Copenhagen, Denmark Correspondence to: SMoon suerie.moon@graduateinstitute.ch

\section{(c) (1) \& 8 OPEN ACCESS}

This is an Open Access article distributed under the terms of the Creative Commons Attribution IGO License (https://creativecommons.org/licenses/ by-nc/3.0/igo/), which permits use, distribution, and reproduction for non-commercial purposes in any medium, provided the original work is properly cited.

\section{Check for updates}

1 PatientView. Corporate reputation of Pharma in 2018 -the patient perspective. 2019. http:// createsend.com/t/j-745C162ED8766EEF2540EF23 F30FEDED

2 Maxwell S. Fair price: research outside marketing. J Prod Brand Manage 2008;17:497-503. doi:10.1108/10610420810916399

3 Bolton LE, Warlop L, Alba JW. Consumer perceptions of price (un)fairness. J Consum Res 2003;29:474-91. doi:10.1086/346244

4 Xia L, Monroe KB, Cox JL. The price is unfair! a conceptual framework of price fairness perceptions. J Mark 2004;68:1-15. . https://pdfs.semanticscholar. org/0afc/86c67c578f532c5267b62b56b6a2d96f 3c8b.pdf. doi:10.1509/jmkg.68.4.1.42733

5 NASDAQ. Definition of "fair price”. NASDAQ financial glossary. https://www.nasdaq.com/investing/ glossary/f/fair-price

6 BusinessDictionary. Definition: fair and reasonable price. http://www.businessdictionary.com/definition/ fair-and-reasonable-price.html
7 Hou L. Excessive prices within EU Competition Law. Eur Compet / 2011;7:47-70 . https://papers.ssrn. com/sol3/papers.cfm?abstract_id=1850569. doi:10.5235/174410511795887606

8 Abbott F. Excessive pharmaceutical prices and competition law: doctrinal development to protect public health. UC Irvine Law Rev 2016;6:281. https:// scholarship.law.uci.edu/ucilr/vol6/iss3/3/

9 Prasad V, Mailankody S. Research and development spending to bring a single cancer drug to market and revenues after approval. JAMA Intern Med 2017;177:1569-75. doi:10.1001/ jamainternmed.2017.3601

10 Sarpatwari A, Avorn J, Kesselheim AS. State initiatives to control medication costs--can transparency legislation help?N Engl J Med 2016;374:2301-4 doi:10.1056/NEJMp1605100

11 Council of Europe Parliamentary Assembly. Resolution 2071, 30th sitting. Public health and the interests of the pharmaceutical industry: how to guarantee the primacy of public health interests? 2015. http://assembly.coe.int/nw/xml/XRef/XrefXML2HTML-en.asp?fileid=22154\&lang=en

12 Saez C. Negotiators agree on game-changing WHA resolution for medicine price disclosure. Health Policy Watch 2019.https://www.healthpolicy-watch. org/negotiators-agree-on-game-changing-wharesolution-for-medicine-price-disclosure/

13 United Nations Secretary-General's High-Level Panel on Access to Medicines. Report of the United Nations Secretary-General's High-Level Panel on Access to Medicines: Promoting innovation and access to health technologies. 2016. http://www. unsgaccessmeds.org/final-report/

14 Wirtz VJ, Hogerzeil HV, Gray AL, et al. Essential medicines for universal health coverage. Lancet 2017;389:403-76. doi:10.1016/S0140 6736(16)31599-9

15 Hill A, Khoo S, Fortunak J, Simmons B, Ford N. Minimum costs for producing hepatitis $C$ directacting antivirals for use in large-scale treatment access programs in developing countries. Clin Infect Dis 2014;58:928-36. doi:10.1093/cid/ciu012

16 Hill AM, Barber MJ, Gotham D. Estimated costs of production and potential prices for the WHO Essential Medicines List. BMJ Glob Health 2018;3:e000571. doi:10.1136/ bmigh-2017-000571

17 Damodaran Archives. Data: Archives. 2019.http:// people.stern.nyu.edu/adamodar/New_Home_Page/ dataarchived.html\#industry

18 Witty A. Transcript from Center for Strategic and International Studies (CSIS): The Bio-Pharma industry and society. 2016.https://csis-prod.s3.amazonaws. com/s3fs-public/event/160317_The_Bio-Pharma_ Industry_and_Society_Transcript.pdf

19 Kessides I, Miniaci R, Scarpa C, et al. Toward defining and measuring the affordability of public utility services. The World Bank, 2009. http://documents.worldbank.org/curated/ en/859201468338935200/Toward-defining-andmeasuring-the-affordability-of-public-utility-services

20 Xu K, Evans DB, Kawabata K, Zeramdini R, Klavus J, Murray CJ. Household catastrophic health expenditure: a multicountry analysis. Lancet 2003;362:111-7. doi:10.1016/S01406736(03)13861-5

21 World Health Organization (WHO) and World Bank Group. Tracking universal health coverage: first global monitoring report. 2015. https://www.who.int/ healthinfo/universal_health_coverage/report/2015/ en/

22 Love J. Affidavit. Natco Pharma Limited versus Bayer Corporation, 2012. https://www.keionline.org/sites/ default/files/aff-jameslove_13Feb2012_as_Filed.pdf

23 Morgan SG, Lee A. Cost-related non-adherence to prescribed medicines among older adults: a cross-sectional analysis of a survey in 11 developed countries. BMJ Open 2017;7:e014287. doi:10.1136/bmjopen-2016-014287 
24 Heller PS. The prospects of creating 'fiscal space' for the health sector. Health Policy Plan 2006;21:75-9. doi:10.1093/heapol/czj013

25 Ottersen T, Elovainio R, Evans DB, et al. Towards a coherent global framework for health financing: recommendations and recent developments. Health Econ Policy Law 2017;12:285-96. doi:10.1017/ S1744133116000505

26 Chatham House Centre on Health Security. Shared responsibilities for health: a coherent global framework for health financing. London: Chatham House, 2014. https://www.chathamhouse.org/ publication/shared-responsibilities-health-coherentglobal-framework-health-financing

27 Abuja decaration on HIV/AIDS, tuberculosis and other related infectious diseases. (OAU/SPS/ ABUJA/3). 2001.https://www.un.org/ga/aids/pdf/ abuja_declaration.pdf

28 Saxenian H, Hecht R, Kaddar M, Schmitt S, Ryckman T, Cornejo S. Overcoming challenges to sustainable immunization financing: early experiences from GAVI graduating countries. Health Policy Plan 2015;30:197205. doi:10.1093/heapol/czu003

29 Garrison LPJr, Kamal-Bahl S, Towse A. Toward a broader concept of value: identifying and defining elements for an expanded cost-effectiveness analysis. Value Health 2017;20:213-6. doi:10.1016/j.jval.2016.12.005

30 Pauwels K, Huys I, Casteels M, Simoens S. Industry perspectives on market access of innovative drugs: the relevance for oncology drugs. Front Pharmacol 2016;7:144. doi:10.3389/ fphar.2016.00144

31 Neumann PJ, Cohen JT. Measuring the value of prescription drugs. N Engl J Med 2015;373:2595-7. doi:10.1056/NEJMp1512009

32 Lakdawalla DN, Doshi JA, Garrison LPJr, Phelps CE, Basu A, Danzon PM. Defining elements of value in health care-a health economics approach: an ISPOR Special Task Force Report. Value Health 2018;21:131 9. doi:10.1016/j.jval.2017.12.007

33 Garner S, Rintoul A, Hill SR. Value-based pricing: l'enfant terrible?Pharmacoeconomics 2018;36:5-6. doi:10.1007/s40273-017-0567-4

34 United States Senate Committee of Finance. The price of Sovaldi and its impact on the US health care system. 2015. https://www.finance.senate.gov/imo/media/ doc/1\%20The\%20Price\%20of\%20Sovaldi $\% 20$ and $\% 2$ Its\%20Impact $\% 20$ on $\% 20$ the $\% 20$ U.S. $\% 20$ Health\%20Care\%20System\%20(Full\%20Report).pdf
35 Unicef. Unicef vaccine procurement overview: priorities, status and way forward. 2015. https:// www.unicef.org/supply/files/3_Overview_of_ UNICEF_Vaccine_Procurement_.pdf

36 World Health Organization (WHO). Local production for access to medical products: developing a framework to improve public health. 2011. https:// www.who.int/phi/publications/local_production policy framework/en/

37 Røttingen J-A, Chamas C, Goyal LC, Harb H, Lagrada $\mathrm{L}$, Mayosi BM. Securing the public good of health research and development for developing countries. Bull World Health Organ 2012;90:398-400 doi:10.2471/BLT.12.105460

38 Moon S. Removing the blindfold on medicines pricing. BMJ 2018;360:k840. doi:10.1136/bmj.k840

39 Morgan SG, Vogler S, Wagner AK. Payers' experiences with confidential pharmaceutical price discounts: a survey of public and statutory health systems in North America, Europe, and Australasia. Health Policy 2017;121:354-62. doi:10.1016/j. healthpol.2017.02.002

Cite this as: BMJ 2020;368:14726

http://dx.doi.org/10.1136/bmj.l4726 